\title{
GOOGLE, TELL ME. IS HE GAY?: Masculinity, Heterosexuality, and Gendered Anxieties in Google Search Queries about Sexuality
}

\author{
(forthcoming in Sociological Perspectives) \\ Emma Mishel \\ New York University \\ emmamishel@nyu.edu \\ Tristan Bridges \\ University of California, Santa Barbara \\ tbridges@soc.ucsb.edu \\ Mónica L. Caudillo \\ University of Maryland \\ caudillo@umd.edu
}

\begin{abstract}
It is difficult to gauge people's acceptance about same-sex sexualities, as responses to questionnaires are prone to social desirability bias. We offer a new proxy for understanding popular concern surrounding same-sex sexualities: prevalence of Google searches demonstrating concern over gay/lesbian sexual identities. Using Google Trends data, we find that Google searches about whether a specific person is gay or lesbian show patterned bias towards masculine searches, in that such searches are much more frequently conducted about boys and men compared to girls and women. We put these findings into context by comparing search frequencies with other popular Google searches about sexuality and otherwise. We put forth that the patterned bias towards masculine searches illustrates support for the enduring relationship between masculinity and heterosexuality, and that it does so on a larger scale than previous research has been able to establish.
\end{abstract}

AUTHORS' NOTE: We would like to thank Paula England, Leila Rupp, and Verta Taylor for detailed feedback on an early draft of this manuscript. Thanks also to Amy Stone and Jo Reger for helping us with an early draft of this manuscript. We also appreciated the editors at Sociological Perspectives and the anonymous reviewers for helpful and detailed feedback. An earlier draft of this paper was presented at the 2019 Sociologists for Women in Society winter meeting in Denver, Colorado. Thanks to the other presenters on our roundtable for a generative discussion that we hope is reflected here as well. 
There are over 3.5 billion Google searches conducted every day (Mangles 2018). Users ask Google to show them new products, to find recipes, or to shed light on myriad questions like: "How tall is the tallest giraffe?," "How do I know if I have the flu?," or “Are ghosts real?" Google search data gives us unique access into social life and can sometimes be used to answer questions more challenging to answer with more traditional sources of data in the social sciences (e.g., Chykina and Crabtree 2018; DiGrazia 2017; Stephens-Davidowitz 2017, 2014a, 2014b).

While some have examined Google search data related to sexuality, such as gender-specific searches for pornography (e.g., Stephens-Davidowitz 2017), less research has examined what else we can learn about sexuality from Google search data. In this paper, we explore how Americans utilize Google to search for sexuality-related questions. In particular, we assess whether there are differences in the volume of Google searches asking about the sexual orientations of men and women. We posit that due to the links between masculinity and heterosexuality, there will be more Google searches asking whether men and boys are gay compared to Google searches asking whether women and girls are gay/lesbian.

Using Google Trends data, we find consistent higher rates of Google searches about possibly gay men and boys compared to the same searches about possibly gay women and girls. This patterned bias towards searches about men and boys occurs across a range of Google search options and phrases. We use "concern" to refer to search interest throughout the paper.

Before describing our results, we provide a short review of theory and scholarship on the relationship between masculinity and heterosexuality. We argue that the search trends we summarize and document broadly support the enduring relationship between masculinity and heterosexuality. In our discussion, we suggest that this relationship may be further explained by connecting with theory and scholarship on two related issues in the sociologies of gender and sexuality: (1) the devaluation of femininity and (2) the “one-act rule" for men's (but not women's) heterosexuality. We suggest that the enduring relationship between masculinity and heterosexuality might be more usefully explained 
by considering how this relationship is related to these other bodies of knowledge. We conclude with a discussion of how the patterns we find in our Google Trends data illustrate what theory and prior scholarship has posited on a larger scale than previous research has been able to establish.

\section{THE RELATIONSHIP BETWEEN MASCULINITY AND HETEROSEXUALITY}

Theoretical work on sexuality has long situated heterosexuality as a central component of masculinity since at least Freud. Masculinity has been theorized as culturally defined in contradistinction to femininity such that masculinity is defined at least as much by what it is not (feminine, gay, weak) as what it is (e.g., Mosse 1996; Corbett 2001; Pascoe 2007). Indeed, a vast body of scholarship documents that, as England summarized, "men 'do gender' by 'doing straight' to make sense to others as men" (2016: 15).

For instance, Solebello and Elliott (2011) show that fathers are very invested in their sons being heterosexual, and explicitly endeavor to help them craft masculine and heterosexual identities. Kane's (2006) research on heterosexual parents' opinions about gender nonconformity in their children is consistent with this larger pattern as well. Interviewing parents, Kane found that they welcomed gender nonconformity in their daughters, but they were universally distressed by boys interested in what Kane termed "icons of femininity" (e.g., dress up in feminine clothes, nail polish, ballet, Barbie dolls) - heterosexual fathers in particular. Recent survey data corroborate these patterns, too: fewer American adults support gender nonconformity in boys than girls, and men express less support of gender nonconformity than women (Horowitz 2017).

Averett (2015) discovered similar sentiments among LGBTQ parents; some LGBTQ parents express anxiety about how they would be perceived by other parents if they resisted traditional gender norms in raising their children; gay dads were especially anxious that others might think they are "turning their sons gay" if they promoted gender non-conforming practices in their children (Averett 2015; see also Biblarz and Stacey 2010). 
Ward (2008, 2015), Carrillo and Hoffman (2016, 2018), and Silva (2017) also document a relationship between masculinity and heterosexuality as intertwined, examining men who have sex with men but identify as straight. Oftentimes, these men attempt to reaffirm their masculinity and their expected role in society at large (Carrillo and Hoffman 2018). Many report enjoying sex with men specifically because it allowed them to "suspend social expectations about masculinity" (Carrillo and Hoffman 2016: 103), reiterating the relationship between masculinity and heterosexuality.

Pascoe and Diefendorf"s (2019) analysis of uses of "no homo" on social media supports these findings as well, documenting how the phrase is used to enable men to bend norms associated with heteromasculine identities while discursively supporting the idea that masculinity and heterosexuality are linked (see also Bridges 2014). Relatedly, as Corbett (2001) argues and Pascoe (2007) shows, the meaning of "faggot" has shifted such that homophobic slurs are traded among boys and young men not to insinuate that they are gay, but that they are "losers." And research on "masculinity threats" continues to document an enduring relationship between heterosexuality and masculinity when men's gender identities are called into question (e.g., Willer, et al 2013; Weaver and Vescio 2015; O’Connor, Ford and Banos 2017; Munsch and Gruys 2018).

As Connell argues, scholars of masculinity must explore "how gender operates for those men most vehemently defined as unmasculine" (1992: 737) to understand the dynamics of masculinities within a system of gender relations stratified by power and inequality. "Hegemonic masculinity" operates as a cultural ideal that works to sustain men's dominance over women and of some men over others, creating a hierarchy of access to resources, status, and power (Connell 1992, 1995; Connell and Messerschmidt 2005; Messerschmidt 2018). But hegemonic masculinity is also an elusive ideal such that no one may actually be able to fully embody it (e.g., Connell 1990). And heterosexuality is a central and often-linked component of the ideal (Eder 1995; McGuffey and Rich 1999; Pascoe 2007; Wilkins 2009; Bridges 2014; Mize and Manago 2018; Worthen 2020; Diefendorf and Bridges 2020). 
For instance, in Messerschmidt's (2000) work on young sexual offenders, he found boys more likely to enact sexual dominance on younger girls as linked with their investments in ideologies of masculinity that situate heterosexual activity as masculinizing (see also Pascoe 2007; Wilkins 2009; Diefendorf 2015). Indeed, Tolman et al. (2003) argue that a great deal of subsequent inequality and violence against women can be explained by early experiences with heterosociality (Phillips 2000) wherein children learn to normalize heterosexuality alongside masculine dominance. This is one reason research has discovered that young men who are sexually victimized struggle identifying as sexually victimized (e.g., Hlavka 2017; Hirsch and Khan 2020).

A common theory used to make sense of this is Pascoe's (2007) conceptualization of "fag discourse" - a form of gender policing through which boys socialize one another into normative masculine behaviors. Pascoe also documented what she calls "compulsive heterosexuality," whereby boys ritualistically enforce heterosexuality with dominating heterosexual sex talk. Survey studies have also long shown that men exhibit more sexual prejudices toward gay people (gay men in particular), same-sex sexual intimacy (again, particularly among men), and gay rights (e.g., Herek 1986; Kite 1984; Kite and Whitley 1996). Research has continued to document this relationship using varied methods and measures (e.g., Herek 2002; Pew Research Center 2017; Schwartz 2010). The relationship between masculinity and heterosexuality is reinforced by entire cultural belief systems (Alden and Parker 2005) and is documented by experimental research on gender gaps in and gendered forms of sexual prejudice (e.g., Willer, et al 2013; Nagoshi, et al 2018). This suggests that the connection between masculinity and heterosexuality exists at the societal level such that various people and groups have a stake in upholding this relationship, even women (see Diefendorf and Bridges 2020 for a recent summary). As a result of the empirical and theoretical support linking masculinity with heterosexuality, we expect there to be more Google searches concerning boy's and men's non-heterosexual identities than about a girl's or woman's non-heterosexual identity.

The data we have allow us to make an argument about the enduring relationship between masculinity and heterosexuality on a new scale by documenting more searches 
asking Google whether men or boys are "gay" compared to analogous searches for women or girls. We suggest that that the relationship between masculinity and heterosexuality that we report in this paper endures, in part, because it is sustained by two other systems upholding the sex/gender/sexuality system (i.e., Westbrook and Schilt 2014) and gender and sexual inequality: 1) society's devaluation of femininity, and 2) the "one-act rule," or the idea that men have less freedom to explore same-sex desire than women without being labeled or perceived as non-heterosexual. Following our findings, we address these ideas in more detail, explaining how they help to explain the Google search trends that we document and theorize interconnections between three substantial bodies of scholarship on gender and sexual identities and inequality.

\section{HYPOTHESIS, DATA, AND METHODOLOGICAL APPROACH}

\section{Hypothesis}

Based on our summary of how masculinity and heterosexuality are culturally linked, we predict that there is greater concern over men and boys potentially being gay compared to women and girls, and that this will be reflected in trends in gendered Google searches that inquire about a particular person's sexual orientation.

\section{What are Google Trends Data?}

Google is a California-based internet company that provides digital products and services, such as online search and advertising. In 2006, Merriam-Webster dictionary officially added the word "Google" as a verb, defining it as "to use the Google search engine to obtain information" (Harris 2006). By 2007, Google had the majority of the search engine market in the United States (Sullivan 2007) and was the most visited multiplatform website in the United States in 2016 with 246 million unique U.S. visitors (Statista 2017). Google continues to dominate the internet search market with roughly 3.5 billion searches per day (Mangles 2018). 
People use Google to ask questions they may not want to ask people they know, and often because it is simply more convenient. Scholars from various fields have used Google Trends data to analyze topics such as regional outbreaks of influenza (Carneiro and Mylonakis 2009), public concern over police violence (Gross and Mann 2017), parental anxieties associated with sons versus daughters (Stephens-Davidowitz 2014b), concerns over being deported (Chykina and Crabtree 2018), the relationship between racist Google searches and voting patterns (Stephens-Davidowitz 2014a), and trends in conspiratorial beliefs (DiGrazia 2017).

Google Trends data can be particularly useful for getting around social desirability bias, or the tendency for people to alter their response to a test, questionnaire, or interview to be viewed favorably by others. On the assumption that most people are able to use Google privately, there is no need for types of self-censorship that have been documented in interviews and on surveys. That is, search engine behavior may reveal things people would be less likely to admit using other methods of data collection.

\section{Analytical Approach}

This study is primarily descriptive, in that we use Google Trends data to demonstrate how patterns in Google searches offer a powerful illustration of the relationship between masculinity and heterosexuality. We do so by assessing the volume of Google searches that ask whether someone in the user's life is gay or lesbian. This article builds on two online essays by Bridges (2016) and Mishel and Caudillo (2017) relying on Google Trends data. Specifically, we use Google Trends data to examine and compare the following searches:

1. Is my husband gay? vs. Is my wife gay/lesbian/a lesbian?

2. Is my boyfriend gay? vs. Is my girlfriend gay/lesbian/a lesbian?

3. Is my dad gay? vs. Is my mom gay/lesbian/a lesbian?

4. Is my son gay? vs. Is my daughter gay/lesbian/a lesbian?

5. Is my brother gay? vs. Is my sister gay/lesbian/a lesbian?

6. Is he gay? vs. Is she gay/lesbian/a lesbian? 
The phrases above all ask Google whether someone in the user's life is gay or lesbian. The person in question is either gendered masculine (husband, boyfriend, dad, son, brother, "he") or feminine (wife, girlfriend, mom, daughter, sister, "she"), allowing comparisons of concern over the possibly gay sexual orientations of men compared to women.

We note that this list does not exhaust all possible gendered searches. But many searches do not meet the minimum threshold of search volume for Google to report the results. So, for instance, searches about grandfathers/grandmothers, nephews/nieces, uncles/aunts all fall below Google's minimum threshold. Similarly, searches relying on "homosexual" and prejudicial epithets associated with gendered sexualities rather than gay/lesbian were similarly much less common. Rather than combining these searches, we rely on the most common searches. For the searches associated with girls/women, we include and combine results for "gay," "lesbian," and "a lesbian." We do so because "gay" is a gender-neutral term that can be used to describe women along with "lesbian" or "a lesbian," and we wanted to make sure we did not omit any relative search volume when analyzing searches about girls and women.

Google Trends data do not allow us to identify the gender of the users conducting the searches. Despite this limitation, these search data do reflect the extent to which gay sexual orientation among boys and men provokes consistently greater levels of concern in the United States relative to equivalent search volume associated with girls and women.

We limit our sample to Google searches conducted in the United States between 2007 to 2020. While Google Trends provides data from 2004 forward, we restrict our sample to the period between 2007-2020 because it was not until 2007 that Google had the majority (more than 50\%) of the search engine market in the United States (Sullivan 2007) at which point the trend data capture the most accurate depiction of search engine behavior among the American public.

We then construct several figures that descriptively plot the relative search interest in the United States from 2007-2020. The trends that we show correspond to a random, and thus unbiased sample of Google searches, categorized and de-identified by 
Google (Google 2018c). Using this sample, search interest is calculated by first dividing the number of queries for the Google search of interest by the total Google searches in the United States during the specified period. Then, values are scaled on a range from 0 to 100 based on the proportion that a search at a given point in time represents relative to the point with the highest popularity within the date range specified (Google 2018a). Spikes seen in trends correspond with peaks in search volume for a given search compared to search volume across the period (Google 2018c). To get a sense of the relative size of the search interest, we compare additional searches to help assess the relative scale of search interest compared to other kinds of search activity.

We first contrast the relative search volume for searches about boys/men to searches about girls/women, to establish gendered differences in searches about sexual orientation. Then, we draw on other relevant Google searches with similar volumes of activity in order to draw comparisons to help assess the relative prevalence of sexualityrelated searches. Comparison searches were selected based on theoretical relevance and the "autocomplete" feature from Google. Google's auto-populated suggestions are based on three criteria: they include the words typed by the user, they have been searched by the user in the past, and they are popular in a user's geographic area (searches deemed "sexual" or "pornographic" are not included by Google's auto-populate algorithm) (Google 2018b). The suggestions received by the "autocomplete" feature when we typed phrases such as "is my husband..." or "is my wife..." were relevant and popular enough to be suggested in two of the five most populated states in the United States-California and New York - as well as Maryland. ${ }^{1}$ These comparisons help us put search volume for sexuality-related searches into perspective compared to other popular searches that people ask Google about friends, partners, or family members.

\section{RESULTS}

Figure 1 displays relative Google search volume regarding a collection of searches conducted in the United States from 2007 to 2020 that ask whether various

\footnotetext{
${ }^{1}$ These three states were used as they were the three states that the authors resided at the time of the study.
} 
gendered statuses are gay or lesbian. Column charts within Figure 1 display average relative Google search interest over this time period for each of the comparisons, while line charts establish sustained gender gaps across the period. Thus, in each of the comparisons, search volume is rescaled to values between 0 and 100 relative to the peak search volume for the search with the highest search volume within the period in each comparison. And columns document a single figure presenting the average search interest relative to that peak for the entire period specified.

Results demonstrate a patterned bias toward searches about possibly gay boys and men compared to analogous searches about possibly gay girls and women. In other words, people turn to Google to ask whether their sons, dads, boyfriends, husbands, brothers, and other boys/men are "gay" at consistently higher rates than analogous searches regarding their daughters, moms, girlfriends, wives, sisters, or other girls/women. Specifically, we find that between 2007 to 2020, people asked Google "is my son gay" more than two times as often as "is my daughter gay/lesbian/a lesbian" (Figure 1). This gendered search gap - where there is higher concern about gay boys/men than gay girls/women - is consistent across all of our search phrases during this period. Searches for "is my boyfriend gay" and "is my brother gay" both had higher relative average search interest, while analogous estimates for gay girlfriends and sisters were less common by a factor of one third and one quarters, respectively. Furthermore, inquiries about gay husbands are more than 1.4 times as common as searches for gay/lesbian wives, and people search "is he gay" more than twice as often as "is she gay." Inquiries about gay parents show a smaller gender difference than the other search phrases. Yet, searches about gay dads are still more common than inquiries about gay/lesbian moms. This may be a product of children being less likely to think of their heterosexual parents as sexual in the first place. Indeed, aside from sibling searches, inquiries about mothers and fathers had the lowest levels of search interest in general using these phrases (see Figure 2).

As Figure 1 shows, some gendered statuses demonstrate larger gaps in relative search volume than others. All of these data, however, show the same consistent pattern: 
greater search volume associated with Google queries about gay boys and men when compared with analogous searches about gay/lesbian girls and women.

Figure 1. Masculine Bias in Sexuality-Related Searches on Google.com, 2007-2020
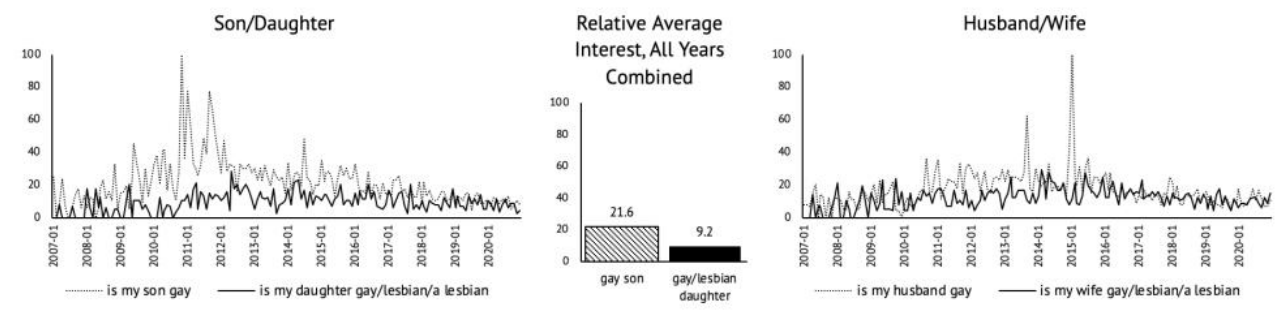

Relative Average
Interest, All Years

Combined
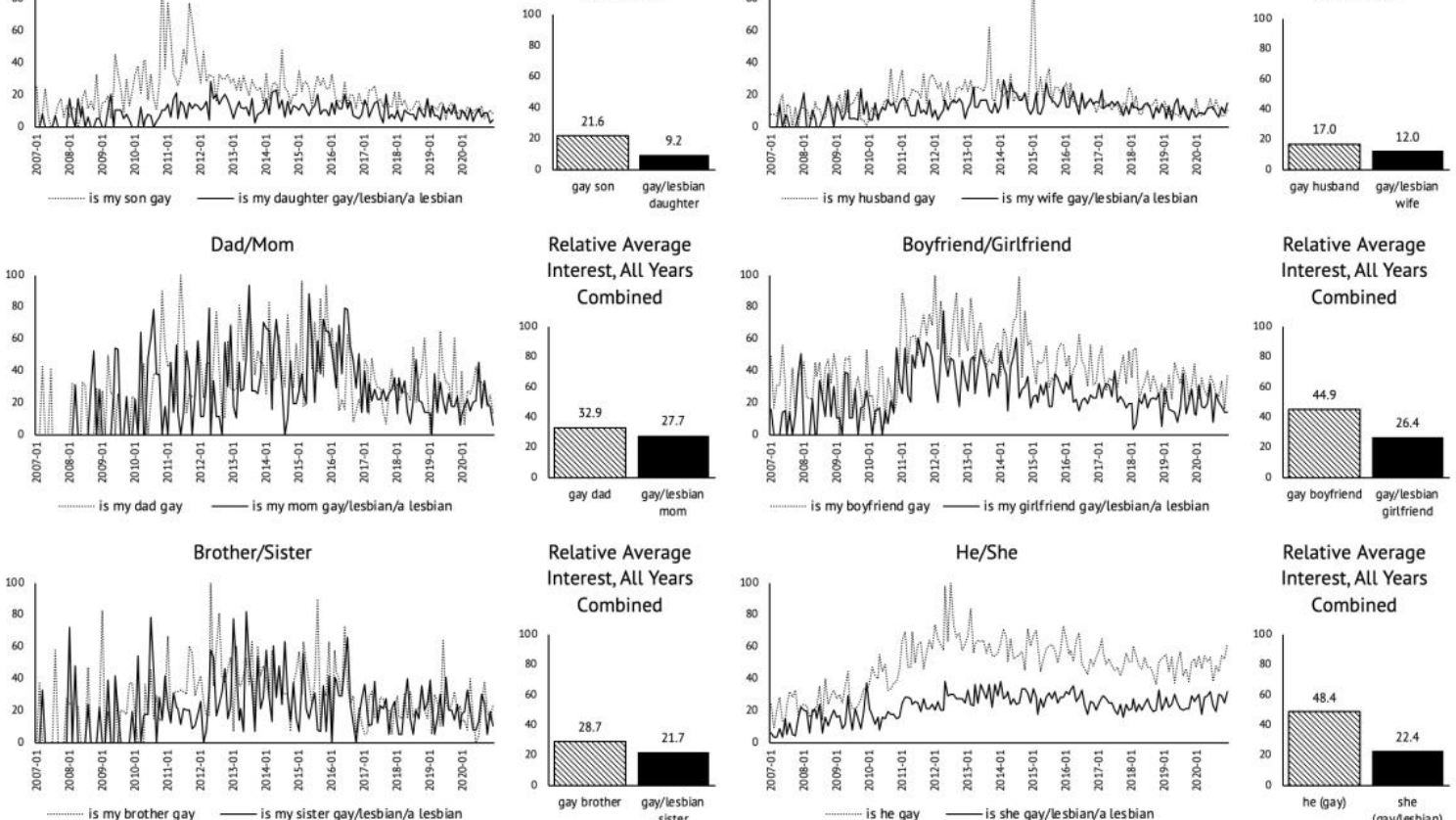

Relative Average Interest, All Years

Combined

Note: Data from Google (2018a). Each point in the line charts represents the search interest relative to the highest point among the selected U.S. searches between January 2007 and December 2020 , where 100 is the peak search popularity across the period, 50 indicates it was half as popular relative to the peak, and 0 means it was less than $1 \%$ as popular. The column charts to the right of each line chart depict average relative search interest over the entire period.

Next, we turn to Figure 2 and compare relative search volume based on gendered classifiers to assess whose sexuality Google users might inquire about most often. We do so by simultaneously comparing average search volumes for inquiries about all of the gendered familial and intimate relationships evaluated above. The most common sexuality-related searches in the United States during the observed period are for sons, boyfriends, and husbands, while the least common are for parents and sisters. Thus, Figure 2 reports average search volume relative to the peak search volume associated with the most common search in this sample and period ("is my son gay"). It makes sense that of all the masculine-gendered searches, searches concerning gay sons were the highest (higher than for gay husbands, boyfriends, brothers, and dads), as parents may be 
more likely to use Google to inquire about their children, their children's future, and/or proper parenting ideology (e.g., Kane 2006, 2012).

Figure 2. Average Relative Search Interest for GenderSpecific Sexuality Searches, 2007-2020

(values scaled to $0-100$ )

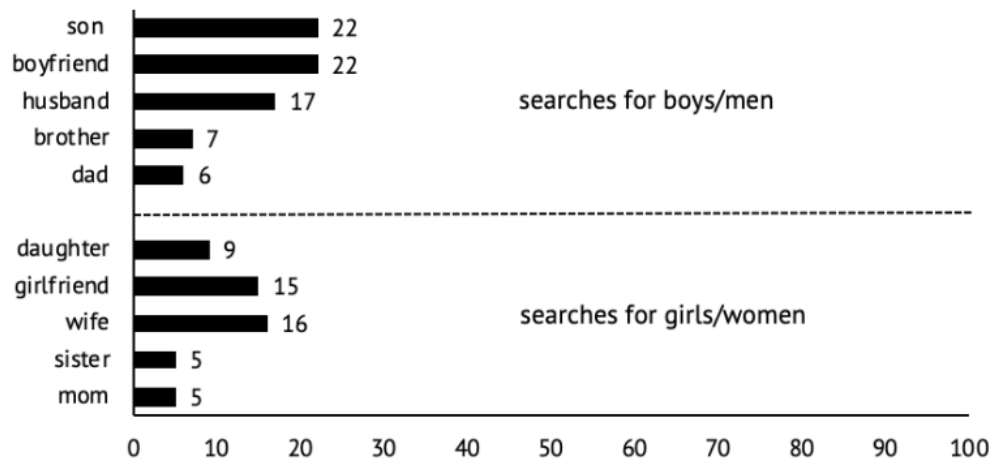

Note: Data from Google (2018a). In a scale from 0 to 100, each bar represents the average search interest relative to the highest point among the selected U.S. searches between January 2007 and December 2020, where 100 is the highest popularity. In this comparison, the peak corresponded to searches for "is my son gay."

In this descriptive analysis, we document search volume over time to demonstrate sustained gaps between gendered searches. Thus, we are less interested in shifts in search volume over time. There are several reasons for this, one of which is that documenting reasons for shifts in search volume can be challenging and often has less to do with our interest in these searches than the gap itself. Taking Google search volume for "is my son gay?" as one example, we can illustrate this point. There are two spikes in search volume for "is my son gay?" over the period we document here (see Figure 1). The first occurs in December of 2010 and is associated with the cinematic release of the film, Oy Vey! My Son is Gay - a film about a Jewish family coming to terms with a son coming out as gay and dating a non-Jewish young man. The second peak occurs in September of 2011 following the release of "Is My Son Gay?"- a controversial app on the Android market which was subsequently taken off the market following protest. In this case, we were able to decipher what increased search volume likely indicated. But in many cases, it is more challenging. Thus, rather than temporal change in search volume, we are here interested in documenting sustained gendered gaps in search volume. 
Similarly, we do not rely on the geographically disaggregated data for common queries that Google makes available. Using this feature, we are able to assess where Google searches are being made, and perhaps of equal importance, where they are not made. We did not report on those data here because, while the searches are not common everywhere, the dispersion of data around the U.S. does not easily lend itself to an argument about why search volume is greater in some states and areas in the U.S. than it is in others. For instance, searches for "is my son gay?" are most common in New Jersey, Massachusetts, New York, Virginia, Florida, California, Illinois, and Texas. While searches for "is he gay?" are slightly more common in the South, the search also exists across the U.S. So, we did not include state-level analyses here because, again, we are primarily interested in documenting sustained gaps over time and noting that search volume is not easily explained by geographic area.

\section{Comparisons to Other Searches}

How do these Google searches about someone's sexual orientation compare to the volume of other searches? This is vital to understand, as we don't know how common asking Google about someone's sexuality is unless we compare these search trends to trends associated with other searches. Thus, we first examine a collection of Google search trends that help to put the gender-differentiated search patterns concerning someone's sexual orientation into context with other sexuality-related searches. For this part of the study, we focus on searches for which we found high gender differences: those corresponding to the sexuality of sons/daughters and husbands/wives.

In Figure 3, we show the relative search volume of "is my son gay" and "is my daughter gay/lesbian" compared to "is my dog gay." We find that the rate at which people ask Google if their daughter is gay is more similar to the rate at which people ask Google if their $\operatorname{dog}$ is gay than it is to queries about whether their son is gay (Figure 3). The relative search volume for the searches "is my cat gay," "is Barney gay" and "is Mr. Rogers gay" also all had similar relative average search volumes to "is my daughter gay/lesbian." 
Figure 3. Relative Search Interest Regarding Childrens'

Sexuality versus Dogs, 2007-2020

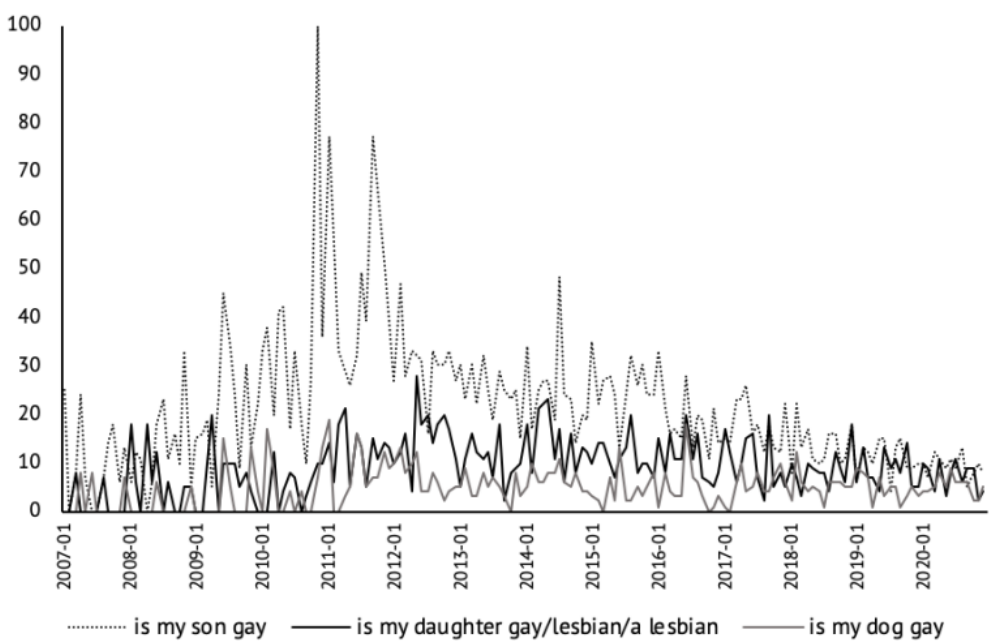

Relative Average Interest, All Years Combined

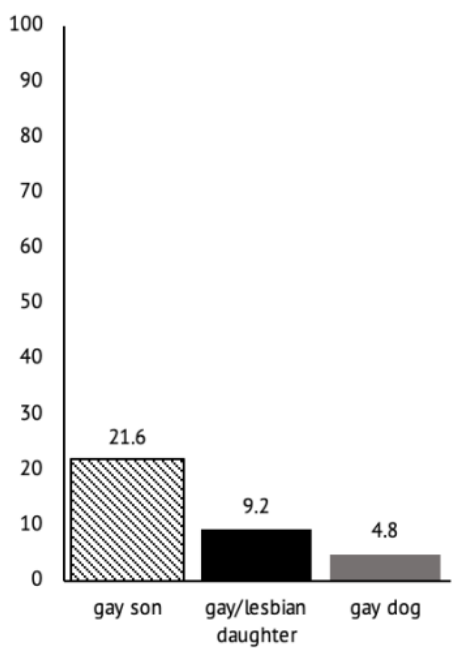

Note: Data from Google (2018a). Each point on the line chart represents the search interest relative to the highest point among the selected U.S. searches between January 2007 and December 2020, where 100 is the peak search popularity across the period, 50 indicates it was half as popular relative to the peak, and 0 means it was less than $1 \%$ as popular. The column chart to the right depicts average relative search interest over the entire period. In this comparison, the peak corresponds to searches for "is my son gay."

These comparisons help put our findings into context. They show how much search interest there is for a given Google search inquiry (e.g. "is my son gay") by evaluating the commonness of searches about someone's sexual orientation relative to one another, and allow us to compare trends to related searches about sexuality we might imagine to be less (or more) common. Indeed, the strategy of offering other searches to help Google Trend data offer more meaning is more commonly utilized by health scholars relying on Google Trend data. It helps to examine how often people use Google to inquire about specific symptoms or diseases relative to others. Health scholars use this method to establish baseline relative levels of disease prevalence in different areas (e.g., Carneiro and Mylonakis 2009). We use the same strategy here to help establish baseline relative levels of sexuality-related search interest.

Next, we examined a collection of non-sexuality-related searches to understand how common searches about sexual orientation are relative to searches not related to sexual orientation. Specifically, we examined other searches that parents might ask Google about their children, such as whether their child is gifted. Figure 4 shows that searches for "is my son gay" are more than 20 times as common as searches for "is my 
son gifted" and more than 70 times as common as searches for "is my daughter gifted." Similarly, we find that parents conduct searches for "is my daughter gay/lesbian" over 30 times more often than "is my daughter gifted." This helps establish how common sexuality-related Google searches are, and suggests that parental concern surrounding children's sexuality, particularly if they are boys, is greater than parental concern surrounding children's levels of giftedness (as measured by Google search volume).

Figure 4. Relative Search Interest Regarding Childrens' Sexuality versus Giftedness, 2007-2020

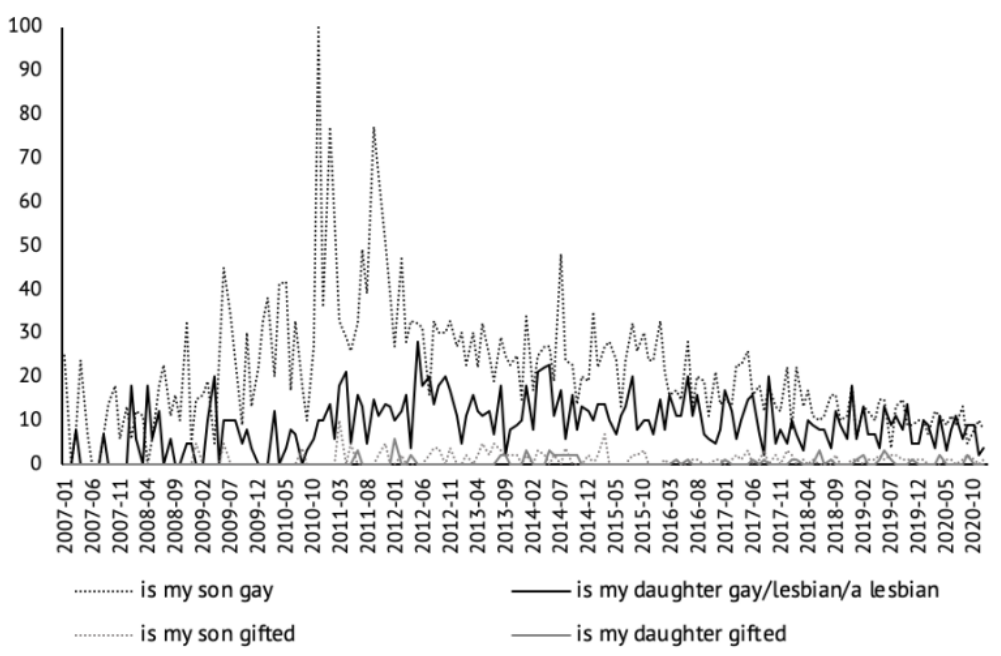

Relative Average Interest, All Years Combined

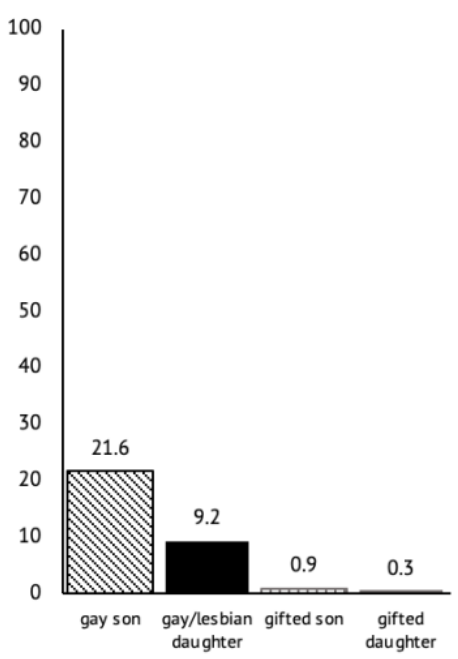

Note: Data from Google (2018a). Each point on the line chart represents the search interest relative to the highest point among the selected U.S. searches between January 2007 and December 2020, where 100 is the peak search popularity across the period, 50 indicates it was half as popular relative to the peak, and 0 means it was less than $1 \%$ as popular. The column chart to the right depicts average relative search interest over the entire period. In this comparison, the peak corresponds to searches for "is my son gay."

This is important because, as Stephens-Davidowitz (2014b) found, parents turn to Google for lots of queries about their children, and search volume shows patterned differences in what parents ask about sons versus daughters. For example, they are more likely to ask Google if their son is "a genius," "gifted," "intelligent," or "a leader" than they are about daughters, and they are more likely to ask Google if their daughters are "overweight," "beautiful," or "ugly" than they are about sons. Yet, as Figure 5 also demonstrates, parental concern with children's sexuality is also far greater than their concern with whether their sons or daughters are "overweight" (again, measured by Google search volume). 
Figure 5. Relative Search Interest Regarding Childrens'

Sexuality versus Status as "Overweight", 2007-2020

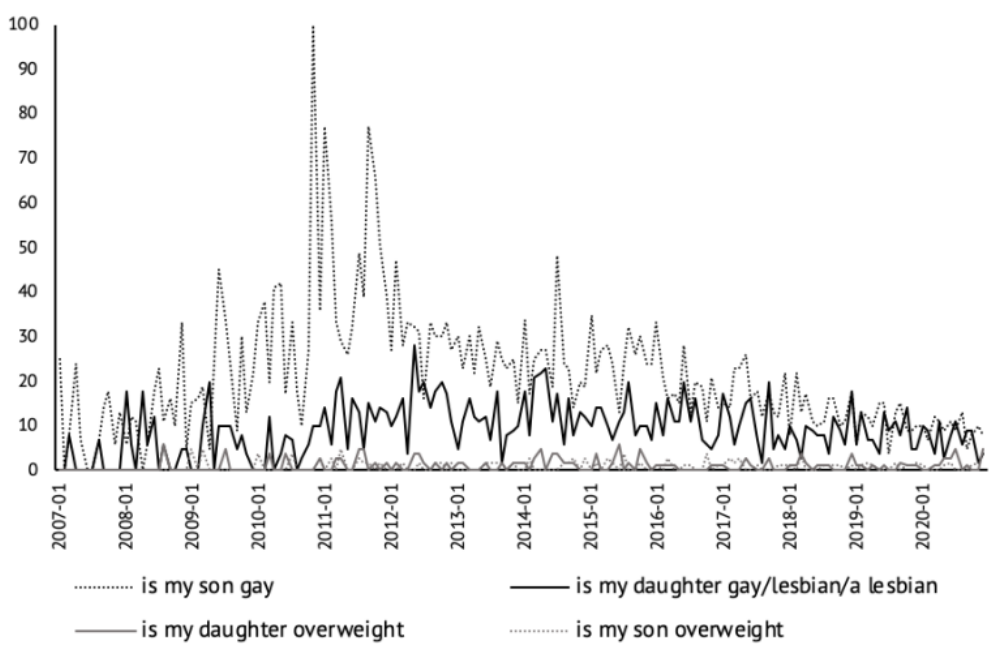

Relative Average Interest, All Years Combined

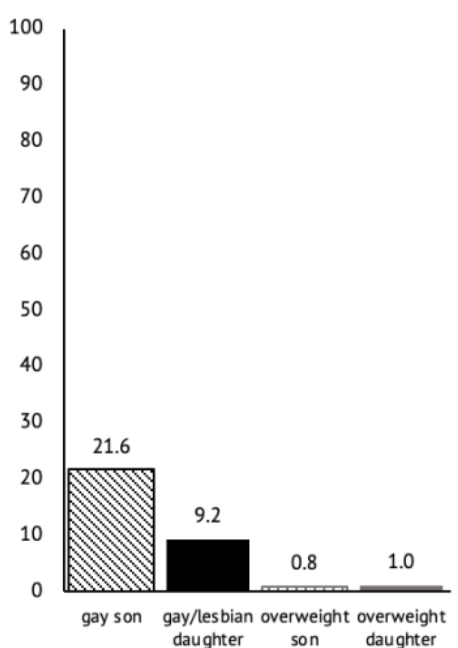

Note: Data from Google (2018a). Each point on the line chart represents the search interest relative to the highest point among the selected U.S. searches between January 2007 and December 2020, where 100 is the peak search popularity across the period, 50 indicates it was half as popular relative to the peak, and 0 means it was less than $1 \%$ as popular. The column chart to the right depicts average relative search interest over the entire period. In this comparison, the peak corresponds to searches for "is my son gay."

Along the same lines, we put search volume about husbands' sexualities into context with other non-sexuality-related searches that people may ask Google about husbands. Figure 6 displays search volume for "is my husband abusive?" and "is my husband happy?" alongside relative search volume for "is my husband gay?" As Figure 6 illustrates, people turn to Google to ask if their husband is gay over two times more often than to ask if their husband is abusive, and roughly 2.4 times more often than to inquire about whether he is happy. 
Figure 6. Relative Search Interest Regarding Husband's

Sexuality versus Abusiveness or Happiness, 2007-2020

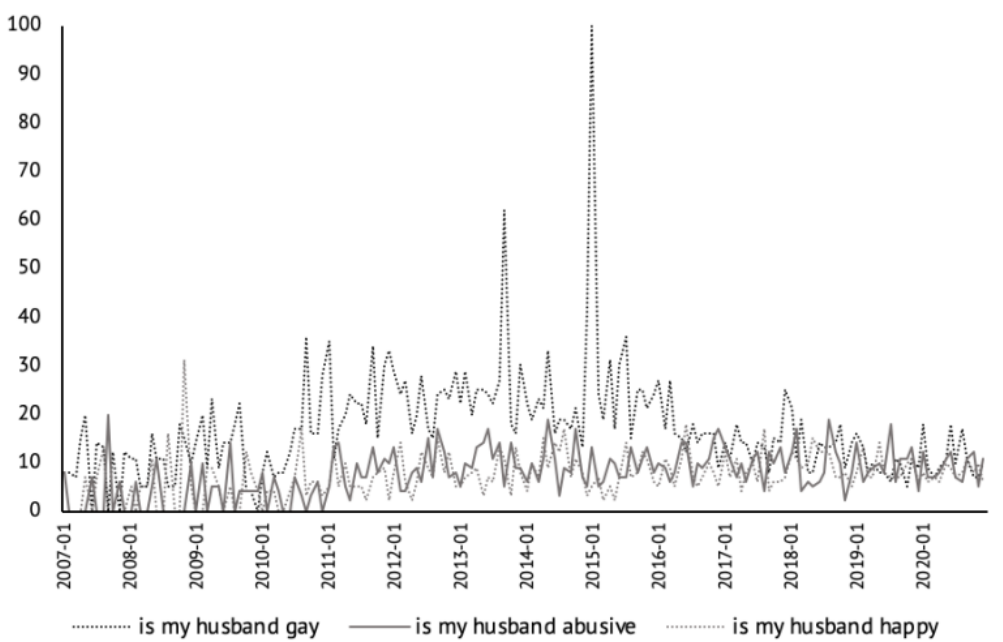

Relative Average Interest, All Years Combined

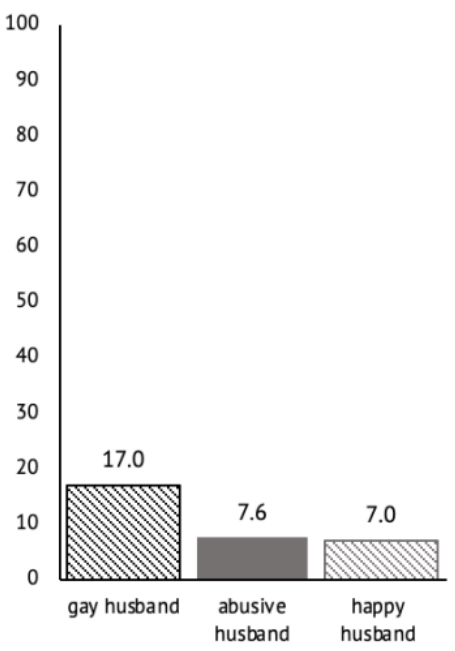

Note: Data from Google (2018a). Each point on the line chart represents the search interest relative to the highest point among the selected U.S. searches between January 2007 and December 2020, where 100 is the peak search popularity across the period, 50 indicates it was half as popular relative to the peak, and 0 means it was less than $1 \%$ as popular. The column chart to the right depicts average relative search interest over the entire period. In this comparison, the peak corresponds to searches for "is my husband gay."

The top autocompleted searches that begin with "is my husband" or "is my wife" on Google are related to infidelity (e.g., "Is my husband/wife cheating," "Is my husband/wife seeing someone else"). But we were interested in establishing a non-sexual search volume baseline associated with common non-sexual searches beginning with the same wording. Husbands do not ask Google about their wives' abusiveness or happiness with the same frequency as wives inquire about their husbands. In fact, most Google searches that auto-populate when typing in "is my wife..." have to do with infidelity or mental health. The top non-sexual search among auto-populated results is, "is my wife a dependent?" (Figure 7). Not surprisingly, search volume associated with this search in the U.S. peak correspond to the end and beginning of each year, as people are putting their taxes together. This is noteworthy because it is a search many married Americans who prepare their taxes may ask Google. Yet, it produced an average relative search volume more than seven times lower than searches for "is my wife gay/lesbian." Thus, searches associated with husbands' abusiveness or happiness and wives' status as dependents help to put into context the volume of the corresponding homosexuality-related searches. 
Figure 7. Relative Search Interest Regarding Wife's

Sexuality versus Status as "a Dependent", 2007-2020

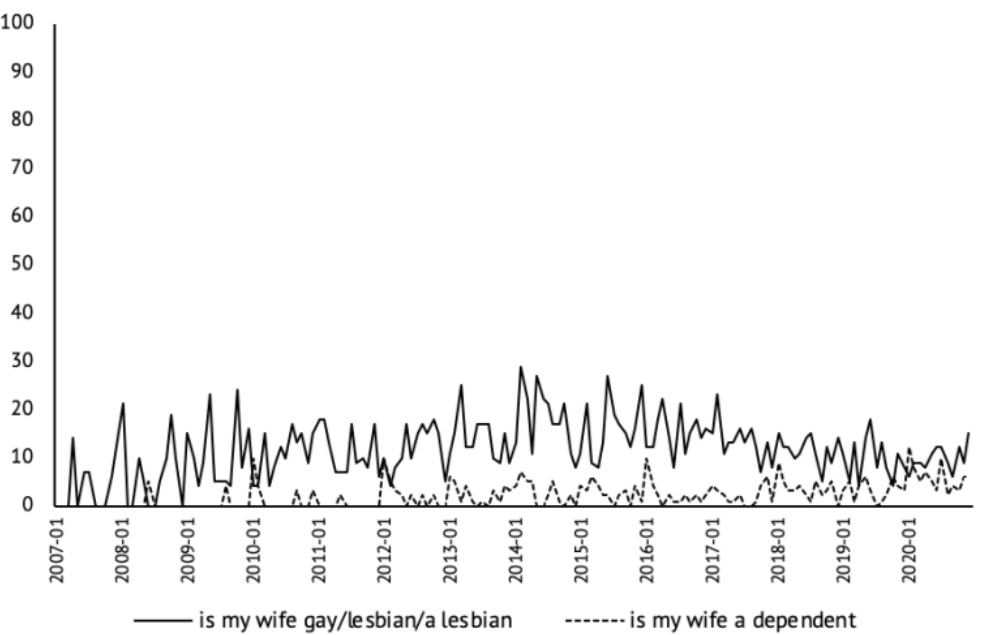

Relative Average Interest, All Years Combined

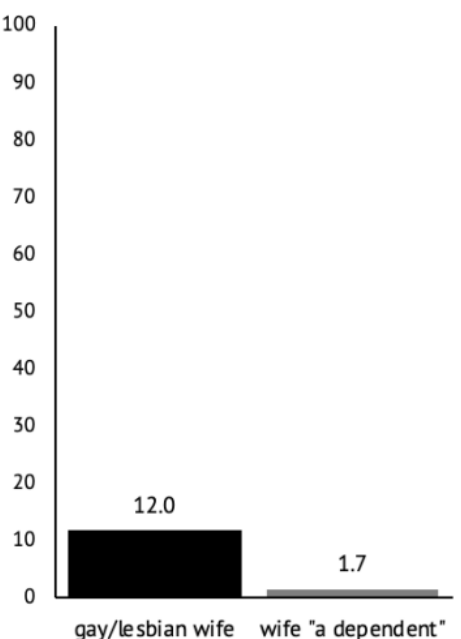

Note: Data from Google (2018a). Each point on the line chart represents the search interest relative to the highest point among the selected U.S. searches between January 2007 and December 2020, where 100 is the peak search popularity across the period, 50 indicates it was half as popular relative to the peak, and 0 means it was less than $1 \%$ as popular. The column chart to the right depicts average relative search interest over the entire period. In this comparison, the peak corresponds to searches for "is my husband gay" (not depicted on this figure).

In sum, we find that there are substantial differences in the volume of Google searches that inquire about men's sexual orientation, compared to women's. Specifically, results demonstrate a patterned bias toward searches about the gay sexual orientation of boys and men when compared to analogous searches about girls and women. This finding is consistent across all the gendered search phrases we analyzed.

In supplementary analysis, we also examined Google search data that asked whether someone was bisexual (instead of gay/lesbian). When doing so, though search volume is lower overall, we find a similar pattern: there are more searches asking whether my "husband," "boyfriend," and "he" is bisexual compared to analogous searches inquiring about whether my "wife," "girlfriend," and "she" is bisexual. (Analogous searches about bisexual parents, siblings, or sons/daughters did not generate enough search volume to assess any Google trends.) We also looked at search data that looked at whether someone was "queer," but such searches did not generate enough search volume to assess any Google trends.

One way of making sense of these data is to suggest that people tend to assume that boys and men are simply more sexual than are girls and women. So, for instance, it 
might be the case that all searches associated with sexuality will be more commonly asked about boys and men than girls and women. While some sexuality-related searches skew masculine, such as Google searches about infidelity (there is higher search volume for "is my husband cheating on me" and "is my boyfriend cheating on me" compared to analogous searches about cheating wives and girlfriends), other sexuality-related searches skew feminine, and thus, this hypothesis is not necessarily supported. For example, in additional supplementary analyses, we find that Google searches for "is my mom having sex," "is my sister having sex," and "is my daughter having sex" are all asked much more than analogous searches concerning dads, brothers, and sons. Specifically, searches for "is my mom having sex" are asked more than twice as often as "is my dad having sex;" searches for "is my sister having sex" are asked 1.75 times more often than "is my brother having sex;" and searches for "is my daughter having sex" are asked 1.5 times as often as "is my son having sex." The disparity between searches for "is my mom having sex" and "is my dad having sex" may partially reflect the prevalence of single motherhood relative to single fatherhood in the U.S. But the fact that searches about daughters and sisters having sex are more popular than those regarding sons and brothers shows that not all sexuality-related searches on Google are more commonly asked about men and boys. Importantly, every gender-specific search about same-sex sexuality we considered here is more frequently asked about boys and men when compared with analogous searches concerning girls and women. And it is for this reason that we argue these findings offer a new kind of broad support for the strong and enduring relationship between masculinity and heterosexuality.

\section{DISCUSSION AND CONCLUSION}

Based on an analysis of searches registered by Google Trends data, our results demonstrate two consistent findings. First, there are consistently higher volumes of searches inquiring about whether boys and men are gay compared to analogous searches for girls and women (though the scale of this difference does differ by different relationships). This gendered bias in search interest does not hold across all sexuality- 
related searches, but is universally true across same-sex sexuality-related searches. Second, the search volume associated with gay sexuality is higher than other, popular and theoretically relevant searches involving the relationship statuses we examine. Thus, we have established both that searches that ask whether someone is "gay" are very common relative to other searches, and that searches inquiring about people's status as gay/lesbian are consistently more commonly associated with boys and men.

Why might people be more concerned about gay men and boys than about gay women and girls? We suggest that the patterned bias toward searches for boys' and men's same-sex sexualities corroborate the large body of sociological theory and empirical research on the enduring relationship between masculinity and heterosexuality. These data suggest that shifting attitudes that are sometimes presented as "sexual progress," might be more accurately reflective of what Walters (2014) calls "sexual tolerance."

Androcentrism and the relationship between masculinity and heterosexuality are integral components of a great deal of theory about the durability of gender and sexual inequality (e.g., Connell 1987, 1995; Demetriou 2001; Pascoe 2007; Bridges 2014; Bridges and Pascoe 2014). As we discussed above, there is much theoretical and empirical support linking masculinity with heterosexuality (e.g., Messerschmidt 2000; Solebello and Elliott 2001; Pascoe 2007; Diefendorf and Bridges 2020) and various societal groups hold a stake in upholding this relationship, even women. We suggest here that the relationship between masculinity and heterosexuality that we document in this paper endures, in part, because it is maintained by two other systems upholding the sex/gender/sexuality system (i.e., Westbrook and Schilt 2014) and gender and sexual inequality: 1) the devaluation of femininity, and 2) the "one-act rule".

Alongside this societal link between masculinity and heterosexuality is society's devaluation of femininity. And, together with both the enduring relationship between masculinity and heterosexuality and the social and cultural devaluation of femininity is another norm: that men's heterosexuality is more easily questioned than women's heterosexuality. The argument is that men have less freedom to explore same-sex desire than women without being labeled or perceived, by others or by themselves, as non- 
heterosexual. We argue here that the enduring relationship between heterosexuality and masculinity is directly connected to the sociological theories and empirical evidence supporting the social and cultural devaluation of femininity and the "one-act rule." Properly appreciating this enduring relationship requires understanding the connections between these three bodies of scholarship.

The Devaluation of Femininity. An enormous body of scholarship has documented the devaluation of femininity, specifically in the U.S. For example, wages are lower in occupations requiring skills culturally associated with women (e.g., nurturance). Similarly, both men's and women's wages decrease when moving from a "male" to a "female"-typed job, net of individual characteristics, occupational skill demands, physical demands of the occupation, hours worked, and occupational industry (Kilbourne et al. 1994). In general, occupations filled mostly by women pay much less than what you could expect them to pay based on demand (Levanon et al. 2009). Furthermore, researchers have documented evidence of a "care penalty" - work associated with women (e.g., childcare, teaching, healthcare, and counseling) pays less than other work requiring the same amount of skill, effort and risk (England and Folbre 2005).

Besides devaluing work associated with women, social scientists have shown that women are generally perceived to have lower status and value in American society than men (Ridgeway 1993; Ridgeway and Correll 2004; England 2016). Indeed, several experimental studies find that women are perceived to be significantly less competent and to have lower overall abilities compared to men with equivalent qualifications and credentials (Biernat and Kobrynowicz 1997; Foschi 1996; Moss-Racusin et al. 2012; Swim et al. 1989), as are mothers when compared to equally qualified fathers (Correll et al. 2007; Cuddy et al. 2004). Similarly, research on androgynous baby names in the U.S. finds that as they become popular, they cease to be given to boys and become names only for girls (Lieberson, Dumais, and Baumann 2000) illustrating a patterned devaluation associated with femininity for boys and men. Relatedly, research shows that transgender 
men receive more authority, respect, and rewards after transitioning from being socially recognized as women to being socially recognized as men (Dozier 2005; Schilt 2006, 2010; Schilt and Wiswall 2008).

Because characteristics associated with women (traits women are believed to have, or activities women often do) are devalued in society (England 2016), men and boys receive greater penalties for breaking with traditional gender norms than women and girls. For example, boys who transgress traditional gender roles by wanting to play with Barbies or knowing how to dance and dress well are subject to more gender policing than girls who break with traditional feminine gender roles by wanting to play with trucks or knowing how to swing a hammer, precisely because femininity is devalued (Pascoe 2007; Messner 2000). Being gay, or exhibiting same-sex sexual desire, is also seen as breaking with traditional gender roles. In this sense, when men exhibit any same-sex sexuality, they are simultaneously breaking traditional gender roles, and are thus seen as feminine. Therefore, it follows that men's heterosexuality is strongly tied to masculinity, while men's homosexuality is tied to femininity.

Policing Sexual Orientation and the "One-Act Rule." As mentioned, gender and sexuality are linked such that when a person engages in same-sex sexual behavior, they are simultaneously seen as transgressing gender boundaries, and when a person transgresses traditional gender boundaries or scripts, it may cause their heterosexuality to be questioned. Because there is more disapproval of gender transgressive behavior for boys and men compared to girls and women (as a result of the devaluation of femininity), same-sex sexual behavior and same-sex desire are also more heavily policed for men and boys than for women and girls (e.g., Kane 2006, 2012; Pascoe 2007). Indeed, experimental research illustrates that people express significantly greater disapproval over gay men couples showing affection in public by kissing or holding hands compared to lesbian couples doing the same (Doan et al. 2014).

In line with these findings, studies show that women are generally more sexually fluid than men in terms of engaging in same-sex sexual behavior. Both large, survey- 
based quantitative studies and qualitative studies using smaller samples show that more women report having same-sex sex and same-sex attraction than men (e.g., Diamond 2008, 2014; England et al. 2016; Gates 2011; Laumann et al. 1994; Mishel et al. 2020; Mishel 2019). Research has also shown that same-sex sexual behavior is sometimes strategically mobilized by heterosexual-identifying women who seek to garner attention from men (Hamilton 2007; Rupp and Taylor 2010). In general, research suggests that society is more accepting of women engaging in same-sex sexuality than men (Doan et al. 2014; Page and Yee 1985; Pascoe 2007; Pelligrini 1992; Watts 2015). This may account for the fact that women are disproportionately more likely to identify as bisexual when compared with men, as well as the fact that smaller proportions of men than women identifying as LGB (e.g., Bridges and Moore 2018; Gates 2014).

Women are also given more freedom to explore same-sex desire without being socially assigned a "lesbian" sexual identity, while men are not granted this same freedom to experiment without being perceived as gay. This process exists to such an extent, as Ward $(2008,2015)$ argues, that heterosexual men have collections of discursive alibis they rely on to engage in same-sex sexual behavior while identifying as straight - a process Ward (2015) refers to as "hetero-exceptionalism" (see also Carrillo and Hoffman 2016, 2018, Silva 2017, 2018a, 2018b and Hoy and Landon 2018). Indeed, research shows that men are more likely to be relabeled "gay" or "bisexual" after a single samesex experience, while women who have a single same-sex sexual experience predominantly retain assumptions of heterosexuality (Mize and Manago 2018). Another study of over 24,000 undergraduate students found that, among those whose last "hook up" was with someone of the same sex, men were much more likely to identify as "gay," "bisexual," or "unsure" than were women (Kuperberg and Walker 2018). Some refer to this idea as the "one drop" rule of homosexuality (Schwartz 1995), the "gender of sexuality" (Schwartz and Rutter 1998), the "one act rule" of homosexuality (Schilt and Westbrook 2009; Ward 2006), men's “precarious heterosexuality” (Mize and Manago 2018) or the "one-time rule" (e.g., Anderson 2008; Scoats et al. 2018). 
Because boys' and men's heterosexuality is more precarious than girls' and women's, and because femininity is devalued, men often do not have as much freedom to explore same-sex desire or to engage in gender transgressions imbued with sexual connotations without social repercussions, being socially assigned a gay sexual orientation, or having their connection with heterosexuality at least questioned. These steeper social costs associated with boys' and men's gender transgressions are powerfully illustrative of the enduring relationship between heterosexuality and masculinity. They are also exactly what we document in our assessment of Google search trends - i.e., that there is greater concern (measured by Google search volume) over men and boys possibly being gay than over women and girls being gay/lesbian. In other words, since femininity is devalued, and since boys' and men's heterosexuality is seen as much more precarious than women's heterosexuality, it follows that people would question the heterosexuality of men and boys in their life more frequently than the women and girls they know. This is exactly what we demonstrate using Google Trends data. In this sense, the patterned bias toward searches for boys' and men's same-sex sexualities corroborate these three interrelated themes underlying a large body of sociological theory and empirical research.

Limitations and Future Research. Google search data may be perceived as an odd place to look for corroborating evidence for these theories. Yet, others have argued that Google search data offer an important place to look for answers to questions on sensitive topics about which survey and even interview data may provide inaccurate results due to social desirability bias (e.g., Stephens-Davidowitz 2014; Chykina and Crabtree 2018). We argue that Google Trends data offer a unique measurement of issue salience surrounding issues related to same-sex sexuality - data that is also not plagued by social desirability bias.

What we cannot demonstrate from our documentation of the relative prevalence of various Google search queries and gender gaps between them, however, is why people type these queries into search engines. This is a limitation of much research attempting to 
quantify various social processes, and one to which this study is subject as well. So, at least part of the search volume might be driven by motivations unrelated to maintaining heteronormativity, such as an interest in helping gay or lesbian relatives or friends fight hate and discrimination. But even in such cases, the greater search volume associated with the sexuality of men and boys suggests that users perceive greater discrimination against gay men and boys, compared to gay women and girls.

Another limitation of this study is that Google Trends data do not allow us to identify the gender of the users conducting the searches. However, for two of the three most popular searches we evaluate, "is my husband gay" and "is my boyfriend gay," we can reasonably assume that the vast majority of interested users are wives and girlfriends, correspondingly. Similarly, we assume that the majority of searches beginning with "is my wife..." and "is my girlfriend..." are conducted by husbands and boyfriends. These particular searches suggest that beyond a generalized greater concern about boys' and men's homosexuality, women in heterosexual relationships are more likely to question their partners' sexual orientation compared to men in heterosexual relationships. This is consistent with a demanding and hegemonic standard for masculinity based on homophobia and the repudiation of femininity. Under such standards, men's sexuality is strictly policed not only by other men, but also by their other-sex romantic partners (under the assumption that boyfriends, girlfriends, husbands, and wives are all equally likely to refer to Google when curious about their partners' sexuality). In contrast, our data do not permit inferring the gender of the users conducting searches about sons, daughters, brothers, sisters, mothers, fathers, or an unidentified "he" or "she." Despite this limitation, however, we argue that search data reflect greater concerns associated with boys' and men's status as possibly gay relative to equivalent concerns regarding girls and women.

Finally, we limited our descriptive analysis of Google searches to only those conducted in the United States. Data associated with similar searches are also common in other English-speaking nations. For instance, Canada, Australia, and the United Kingdom all show similar gender gaps in the searches we considered here. In fact, while searches 
for gay sons were more common in Canada, Australia, and the U.K. than searches for gay/lesbian daughters, search volume for gay/lesbian daughters were so infrequent in Canada and Australia that Google does not report the search rates. Future research might build on this to consider results associated with trends in search data in other nations. Coming up with analogous searches for different societies around the world might offer us new measurements of awareness of, anxiety around, and interest in same-sex sexualities around the world.

Conclusion. In this paper, we used Google Trends data to test whether there is greater concern over the potential gay/lesbian identities of men and boys compared to women and girls. Evidence presented here is consistent with this hypothesis; there are consistently higher volumes of searches inquiring about whether boys and men are gay compared to analogous searches for girls and women. We also find that search volume associated with gay sexuality is higher than other, popular and theoretically relevant searches involving the relationship statuses we examine. These results reflect an enduring relationship between masculinity and heterosexuality, which constrains boys' and mens' freedom to engage in gender transgression.

\section{REFERENCES}

Alden, Helana L. and Parker, Karen F. 2005. Gender Role Ideology, Homophobia and Hate Crime: Linking Attitudes to Macro-level Anti-gay and Lesbian Hate Crimes. Deviant Behavior 26: 321-343.

Anderson Eric. 2008. "Being masculine is not about who you sleep with ...": Heterosexual athletes contesting masculinity and the one-time rule of homosexuality. Sex Roles 58: 104-115.

Averett, Kate Henley. 2015. The Gender Buffet: LGBTQ Parents Resisting Heteronormativity. Gender \& Society 30: 189-212.

Biblarz, Timothy J., and Judith Stacey. 2010. How Does the Gender of Parents Matter? Journal of Marriage and Family 72: 3-22. 
Biernat, Monica and Diane Kobrynowicz. 1997. Gender- and Race-Based Standards of Competence: Lower Minimum Standards but Higher Ability Standards for Devalued Groups. Journal of Personality and Social Psychology 72: 544-557.

Bridges, Tristan. 2014. A Very “Gay” Straight?: Hybrid Masculinities, Sexual Aesthetics, and the Changing Relationship between Masculinity and Homophobia. Gender \& Society 28: 58-82.

Bridges, Tristan, and C.J. Pascoe. 2015. Masculinities and Post-Homophobias? In Exploring Masculinities: Identity, Inequality, Continuity, and Change, edited by C.J. Pascoe and Tristan Bridges. New York, NY: Oxford University Press.

Bridges, Tristan. 2016. Google, Tell Me. Is My Son Gay?, Sociological Images (blog), June 27, 2016, https://thesocietypages.org/feminist/2016/06/27/google-tell-me-ismy-son-gay/.

Bridges, Tristan and Mignon Moore. 2018. Young Women of Color and Shifting Sexual Identities. Contexts 18: 86-88.

Carrillo, Hector and Amanda Hoffman. 2016. "From MSM to heteroflexibilities: Nonexclusive straight male identities and their implications for HIV prevention and health promotion." Global Public Health 11(7-8): 923-936.

Carrillo, Hector and Amanda Hoffman. 2018. "Straight with a pinch of bi': The construction of heterosexuality as an elastic category among adult US men." Sexualities 21: 90-108.

Carneiro, Herman A., and Mylonakis, E. 2009. Google Trends: A Web-Based Tool for Real-Time Surveillance of Disease Outbreaks. Clinical Infectious Diseases 49: $1557-1564$.

Chykina, Volha and Charles Crabtree. 2018. Using Google Trends to Measure Issue Salience for Hard-to-Survey Populations. Socius 4: 1-3.

Connell, Raewyn. 1987. Gender and Power. Stanford, CA: Stanford University Press.

Connell, Raewyn. 1990. "An Iron Man: The Body and Some Contradictions of Hegemonic Masculinity.” Pp. 83-95 in Sport, Men, and the Gender Order, edited by M.A. Messner and D.F. Sabo. Champaign, IL: Human Kinetics Books. 
Connell, Raewyn. 1992. "A Very Straight Gay: Masculinity, Homosexual Experience, and the Dynamics of Gender." American Sociological Review 57(6): 735-751.

Connell, Raewyn. 1995. Masculinities. Stanford, CA: Stanford University Press.

Connell, Raewyn. \& Messerschmidt, J. W. 2005. "Hegemonic Masculinity: Rethinking the Concept." Gender \& Society 19(6): 829-859.

Corbett, Ken. 2001. Faggot = Loser. Studies in Gender and Sexuality 2: 3-28.

Correll, Shelley J., Stephen Benard, and Stephen Benard In Paik. 2007. Getting a Job: Is There a Motherhood Penalty? American Journal of Sociology 112:1297-1339.

Cuddy, Amy J. C., Susan T. Fiske, and Peter Glick. 2004. When Professionals Become Mothers, Warmth Doesn't Cut the Ice. Journal of Social Issues 60:701-718. Demetriou, Demetrakis. 2001. "Connell's Concept of Hegemonic Masculinity: A Critique." Theory \& Society 30(3): 337-361.

Diamond, Lisa M. 2008. Sexual Fluidity: Understanding Women's Love and Desire. Cambridge, MA: Harvard University Press.

Diamond, Lisa M. 2014. “Gender and Same-Sex Sexuality.” In APA Handbook of Sexuality and Psychology, Vol. 1, Person-Based Approaches, edited by D. L. Tolman and L. M. Diamond. Washington, DC: American Psychological Association.

Diefendorf, Sarah. 2015. "After the Wedding Night: Sexual Abstinence and Masculinities over the Life Course." Gender \& Society 29(5): 647-669.

Diefendorf, Sarah and Tristan Bridges. 2020. "On the Enduring Relationship between Masculinity and Homophobia." Sexualities 23(7): 1264-1284.

DiGrazia, Joseph. 2017. The Social Determinants of Conspiratorial Ideation. Socius 3: 19.

Doan, Long, Annalise Loehr, and Lisa R. Miller, 2014. Formal Rights and Informal Privilege for Same-Sex Couples: Evidence from a National Survey Experiment. American Sociological Review 79: 1172-1195.

Dozier, Raine. 2005. "Beards, Breasts, and Bodies: Doing Sex in a Gendered World." Gender \& Society 19(3): 297-316. 
Eder, D., with Evans, C. C. and Parker, S. 1995. School Talk. New Brunswick, NJ: Rutgers University Press.

England, Paula and Nancy Folbre. 2005. Gender and economic sociology. In The Handbook of Economic Sociology, edited by N. J. Smelser and R. Swedberg. New York, NY: Russell Sage Foundation.

England, Paula, Emma Mishel, and Mónica L. Caudillo. 2016. Increases in Sex with Same-Sex Partners and Bisexual Identity Across Cohorts of Women (but Not Men). Sociological Science 3: 951-970.

England, Paula. 2016. "Sometimes the Social Becomes Personal: Gender, Class and Sexualities." American Sociological Review 81(1): 4-28.

Foschi, Martha. 1996. Double standards in the evaluation of men and women. Social Psychology Quarterly 59: 237-254.

Gates, Gary. 2011. How Many People are Lesbian, Gay, Bisexual, and Transgender? The Williams Institute, April 2011.

Gates, Gary T. 2014. LGBT Demographics: Comparisons among Population-Based Surveys. The Williams Institute, September 2014.

Google. 2018a. Google Trends. Google.com. https://trends.google.com.

Google. 2018b. Google Search Help: Search using autocomplete, Google.com. https://support.google.com/websearch/answer/106230?co=GENIE.Platform\%3D Android\&hl=en

Google. 2018c. Google Trends Help. https://support.google.com/trends/answer/4365533?hl=en

Gross, Neil, and Marcus Mann. 2017. Is There a “Ferguson Effect?" Google Searches, Concern about Police Violence, and Crime in U.S. Cities, 2014-2016. Socius 3: $1-16$.

Hamilton, Laura. 2007. Trading on Heterosexuality: College Women's Gender Strategies and Homophobia. Gender \& Society 21: 145-172.

Harris, Scott D. 2006. Dictionary adds verb: to google. San Jose Mercury News, 7 July. 
Herek, Gregory M. 1986. On Heterosexual Masculinity: Some Psychical Consequences of the Social Construction of Gender and Sexuality. American Behavioral Scientist 29: 563-577.

Herek, Gregory M. 2002. Gender Gaps in Public Opinion about Lesbians and Gay Men. Public Opinion Quarterly 66: 40-66.

Hirsch, Jennifer and Shamus Khan. 2020. Sexual Citizens. New York: W.W. Norton.

Horowitz, Juliana Menasce. 2017. Most Americans see value in steering children toward toys, activities associated with the opposite gender. The Pew Research Center. http://www.pewresearch.org/fact-tank/2017/12/19/most-americans-see-value-insteering-children-toward-toys-activities-associated-with-opposite-gender/.

Hoy, Aaron and Andrew S. London. 2018. "The Experience and Meaning of Same-Sex Sexuality among Heterosexually Identified Men and Women: An Analytic Review." Sociology Compass 12(7).

Hlavka, Heather. 2017. "Speaking of Stigma and the Silence of Shame: Young Men and Sexual Victimization." Men and Masculinities 20(4): 482-505.

Kane, Emily. 2006. "No Way My Boys Are Going to Be Like That!”: Parents' Responses to Children's Gender Nonconformity. Gender \& Society 20: 149-176.

Kane, Emily. 2012. The Gender Trap: Parents and the Pitfalls of Raising Boys and Girls. New York, NY: NYU Press.

Kilbourne, Barbara, Paula England, George Farkas, Kurt Beron, and Dorothea Weir. 1994. Returns to skills, compensating differentials, and gender bias: Effects of occupational characteristics on the wages of white women and men. American Journal of Sociology 100: 689-719.

Kite, Mary E. 1984. Sex Differences in Attitudes toward Homosexuals: A Meta-Analytic Review. Journal of Homosexuality 10: 69-81.

Kite, Mary E. and Bernard E. Whitley, Jr. 1996. Sex Difference in Attitudes Toward Homosexual Persons, Behaviors, and Civil Rights: A Meta-analysis. Personality and Social Psychology Bulletin 22: 336-353. 
Kuperberg, Arielle and Alicia M. Walker. 2018. Heterosexual College Students Who Hookup with Same-Sex Partners. Archives of Sexual Behavior 4: 1-17.

Levanon, Asaf, Paula England, and Paul Allison. 2009. Occupational Feminization and Pay: Assessing Causal Dynamics Using 1950-2000 U.S. Census Data. Social Forces 88: 865-891.

Laumann, E. O., Gagnon, J. H., Michael, R. T., \& Michaels, S. 1994. The Social Organization of Sexuality: Sexual Practices in the United States. Chicago, IL: University of Chicago Press.

Lieberson, Stanley, Susan Dumais, and Shyon Baumann. 2000. The Instability of Androgynous Names: The Symbolic Maintenance of Gender Boundaries. American Journal of Sociology 105: 1249-1287.

Mangles, Carolanne. 2018. Search Engine Statistics 2018, SmartInsights.com. https://www.smartinsights.com/search-engine-marketing/search-engine-statistics/.

McGuffey, C. S. and Rich, B. L. 1999. "Playing in the Gender Transgressive Zone: Race, Class, and Hegemonic Masculinity in Middle Childhood." Gender \& Society 13(5): 608-627.

Messerschmidt, J. W. 2018. Hegemonic Masculinity: Formulation, Reformulation, and Amplification. Lanham, MD: Rowman \& Littlefield.

Messner, Michael. 2000. Barbie Girls vs. Sea Monsters: Children Constructing Gender. Gender \& Society 14: 765-784.

Mishel, Emma and Mónica L. Caudillo. 2017. Google Searches Show More Worry over Gay Men and Boys than over Gay Women and Girls, Contexts: Understanding People in their Social Worlds (blog), November 8, 2017. https://contexts.org/blog/google-searches-show-more-worry-over-gay-men-andboys-than-over-gay-women-and-girls/.

Mishel, Emma, Paula England, Jessie Ford, and Mónica L. Caudillo. 2020. "Cohort Increases in Sex with Same-Sex Partners: Do Trends Vary by Gender, Race, and Class?" Gender \& Society 34(2): 178-209. DOI: https://doi.org/10.1177/0891243219897062. 
Mishel, Emma. 2019. "Intersections between Sexual Identity, Sexual Attraction, and Sexual Behavior among a Nationally Representative Sample of American Men and Women." Journal of Official Statistics 35(4): 859-884. DOI: https://doi.org/10.2478/jos-2019-0036.

Mize, Trenton D., and Manago, Bianca. 2018. Precarious Sexuality: How Men and Women Are Differentially Categorized for Similar Sexual Behavior. American Sociological Review 83: 305-330.

Mosse, George. 1996. The Image of Man: The Creation of Modern Masculinity. New York, NY: Oxford University Press.

Moss-Racusin, Corinne A., John F. Dovidio, Victoria L. Brescoll, Mark J. Graham, and Jo Handelsman. 2012. Science Faculty's Subtle Gender Biases Favor Male Students. Proceedings of the National Academy of Sciences 190: 16474-16479.

Munsch, C. and Gruys, K. 2018. "What Threatens, Defines: Tracing the Symbolic Boundaries of Contemporary Masculinity.”Sex Roles, 79, 375-392.

Nagoshi, Craig T., Cloud, J. R., Lindley, L. M., Nagoshi, J. L., and Lothamer, L. J. 2018. "A Test of the Three-Component Model of Gender-Based Prejudices." Sex Roles, $80,137-146$.

O'Connor, E. C., Ford, T. E., and Banos, N. C. (2017). "Restoring Threatened Masculinity." Sex Roles, 77, 567-580.

Page, Stewart and Mary Yee. 1985. Conception of Male and Female Homosexual Stereotypes among University Undergraduates. Journal of Homosexuality 12: $109-118$.

Pascoe, C.J. 2007. Dude You're A Fag: Masculinity and Sexuality in High School. Berkeley, CA: University of California Press.

Pascoe, C.J. and Sarah Diefendorf. 2019. "No Homo: Gendered Dimensions of Homophobic Epithets Online." Sex Roles 80: 123-136.

Pelligrini, Ann. 1992. S(h)ifting the terms of Hetero/sexism: Gender, power, homophobia. In Homophobia: How We All Pay the Price, edited by W.J. Blumenfeld. Boston, MA: Beacon Press. 
Pew Research Center. 2017. Changing Attitudes on Gay Marriage: Public Opinion on Same-Sex Marriage, Pew Research Center | Religion \& Public Life. http://www.pewforum.org/fact-sheet/changing-attitudes-on-gay-marriage/.

Phillips, Lynn. 2000. Flirting with Danger: Young Women's Reflections on Sexuality and Domination. New York, NY: New York University Press.

Ridgeway, Cecilia. 1993. Gender, status and the social psychology of expectations. pages In Theory on Gender, edited by Paula England. New York, NY: Aldine de Gruyter.

Ridgeway, Cecilia L. and Shelley J. Correll. 2004. Unpacking the gender system: A theoretical perspective on gender beliefs and social relations. Gender \& Society 18: $510-531$.

Rupp, Leila J., and Verta Taylor. 2010. "Straight Girls Kissing.” Contexts 9 (3): 28-32. https://doi.org/10.1525/ctx. 2010.9.3.28.

Scoats, Ryan, Lauren J. Joseph, and Eric Anderson. 2018. “I Don’t Mind Watching Him Cum": Heterosexual Men, Threesomes, and the Erosion of the One-Time Rule of Homosexuality. Sexualities 21: 30-48.

Schilt, Kristen. 2006. Just One of the Guys?: How Transmen Make Gender Visible at Work. Gender \& Society 20: 465-490.

Schilt, Kristen and Matthew Wiswall. 2008. "Before and After: Gender Transitions, Human Capital, and Workplace Experiences." The B.E. Journal of Economic Analysis \& Policy 8(1): 1-26.

Schilt, Kristen and Laurel Westbrook. 2009. Doing Gender, Doing Heteronormativity: "Gender Normals," Transgender People, and the Social Maintenance of Heterosexuality. Gender \& Society 23: 440-464.

Schwartz, Jason. 2010. Investigating Differences in Public Support for Gay Rights Issues. Journal of Homosexuality 57: 748-759.

Schwartz, Pepper. 1995. "The science of sexuality still needs social science.” The Scientist 9(3), 12. Retrieved October 2018. (https://www.the- 
scientist.com/opinion-old/the-science-of-sexuality-still-needs-social-science58648).

Schwartz, Pepper, and Virginia Rutter. 1998. The Gender of Sexuality. Walnut Creek, CA: AltaMira Press.

Silva, Tony. 2017. "Bud-sex: Constructing normative masculinity among rural straight men that have sex with men." Gender and Society 31(1): 51-73.

Silva, Tony. 2018a. “'Helpin' a Buddy Out': Perceptions of Identity and Behavior among Rural Straight Men that Have Sex with Each Other.” Sexualities 21: 68-89.

Silva, Tony J. 2018b. "Straight Identity and Same-Sex Desire: Conservatism, Homophobia, and Straight Culture." Social Forces 97 (3): 1067-94. https://doi.org/10.1093/sf/soy064.

Solebello, Nicholas and Sinikka Elliott. 2011. "We want them to be as heterosexual as possible: Fathers talk about their teen children's sexuality." Gender \& Society 25(3): 293-315.

Statista. 2017. Google - Statistics and Facts, Statista.com. https://www.statista.com/topics/1001/google/.

Stein, Arlene. 2005. Make Room for Daddy: Anxious Masculinity and Emergent Homophobias in Neopatriarchal Politics. Gender \& Society 19: 601-620.

Stephens-Davidowitz, Seth. 2017. Everybody Lies: Big Data, New Data, and What the Internet Can Tell Us About Who We Really Are. New York, NY: HarperCollins.

Stephens-Davidowitz, Seth. 2014a. "The Cost of Racial Animus on a Black Candidate: Evidence Using Google Search Data." Journal of Public Economics 118: 26-40. Stephens-Davidowitz. 2014b. “Google, Tell Me. Is My Son a Genius?” The New York Times, Sunday Review, 18 January. https://www.nytimes.com/2014/01/19/opinion/sunday/google-tell-me-is-my-sona-genius.html.

Sullivan, Danny. 2007. Nielsen NetRatings: August 2007 Search Share Puts Google On Top, Microsoft Holding Gains. SearchEngineLand.com. 
https://searchengineland.com/nielsen-netratings-august-2007-search-share-putsgoogle-on-top-microsoft-holding-gains- 12243 .

Swim, Janet, Eugene Borgida, Geoffrey Maruyama, and David G. Myers. 1989. Joan McKay versus John McKay: Do Gender Stereotypes Bias Evaluations. Psychological Bulletin 105: 409-429.

Tolman, Deborah L., Renée Spencer, Myra Rosen-Reynoso, and Michelle V. Porche. 2003. "Sowing the Seeds of Violence in Heterosexual Relationships: Early Adolescents Narrate Compulsory Heterosexuality." Journal of Social Issues 59(1): 159-178.

Walters, S. 2014. The Tolerance Trap. New York: New York University Press.

Watts, Alexander W. 2015. Sexuality, Gender, and Morality: Testing an Integrated Theory of Anti-Gay Prejudice. Ph. D. diss., Stanford University, Stanford, CA.

Ward, Jane. 2006. Straight dude seeks same: Mapping the relationship between sexual identities, Practices, and cultures. In Sex matters: The sexuality and society reader, 2nd ed., edited by Mindy Stombler. Needham Heights, MA: Allyn \& Bacon.

Ward, Jane. 2008. Dude-Sex: White Masculinities and "Authentic" Heterosexuality Among Dudes Who Have Sex with Dudes. Sexualities 11:414-434.

Ward, Jane. 2015. Not Gay: Sex Between Straight White Men. New York, NY: New York University Press.

Weaver, K. S. and Vescio, T. K. 2015. "The Justification of Social Inequality in Response to Masculinity Threats." Sex Roles 72: 521-535.

Westbrook, Laurel and Kristen Schilt. 2014. "Doing Gender, Determining Gender: Transgender People, Gender Panics, and the Maintenance of the Sex/Gender/Sexuality System." Gender \& Society 28(1): 32-57.

Wilkins, A. C. 2009. "Masculinity Dilemmas: Sexuality and Intimacy Talk among Christians and Goths." Signs 34: 343-368. 
Willer R., Rogalin, C., Conlon, B., \& Wojnowicz, M. 2013. Overdoing Gender: A Test of the Masculine Overcompensation Thesis. American Journal of Sociology 118: 980-1022.

Worthen, Meredith G. F. 2020. "The Young and the Prejudiced? Millennial Men, 'Dude Bro' Disposition, and LGBTQ Negativity in a US National Sample." Sexuality Research and Social Policy, May. https://doi.org/10.1007/s13178-020-00458-6. 